\title{
Ethical aspects
} of donor insemination

\author{
G R Dunstan Department of Moral and Social Theology, King's College, London
}

Professor Dunstan has selected certain aspects of the preceding papers on artificial insemination by donor and subjected these to the scrutiny of a moral theologian.

A journal of medical ethics is likely to be judged by three criteria: by the discernment with which medical procedures are selected for consideration; by the elegance and accuracy with which they are presented; and by the quality of the ethical commentary offered upon them. The choice of artificial insemination as the procedure to be examined in this first number of a new journal may be questioned on the ground that, while it is so much discussed, there is so little new to say. The choice will be approved, however, if it can direct attention to the issues; if it can, in short, channel the diffused discussion into more sharply defined areas and more precise terms.

This is not a task for the ethical commentator alone. Medical practitioners, perhaps, reading the account of the procedures, may well see points of a scientific or clinical nature requiring clarification, further study, further investigation. This is one object of scientific reporting - an ethical requirement in contemporary practice - to submit one's own work to the judgment of peers and to the possibility of development, improvement, or incorporation into the work of others. There are no zones of restricted entry in valid medical science. But reporting of this sort is commonly done in the existing journals; it would be only a secondary purpose, possibly only a byproduct, in a journal of medical ethics, unless scientific or clinical clarification were pursued for the sake of clarifying the attendant ethical issues. It looks as though the ethical commentator, although he has not the sole responsibility, has nevertheless a major responsibility for carrying the discussion forward in the direction required; although, again, ethical commentary may properly be expected among the practitioners themselves as well as from a sympathetic bystander from another discipline.

The ethics of artificial insemination in general have been ventilated in two recent publications in Britain (Wolstenholme and Fitzsimmons, 1973; Jones and Bodmer, 1974), as well as in a considerable interrelated literature in the USA (eg, Ramsey, 1970; Curran, 1973; Dunstan, 1974). It would be tedious to recapitulate those treatments herev Comment is limited to points raised in the papers. in this number of the journal although all of then? are pursued further in the literature cited.

\section{Commercial sperm banking}

Mr Frankel's paper on commercial sperm banking. opens with a sketch of circumstances contributing to the demand - an estimated $30 \%$ infertility in at marriages in the USA, and resort to vasectomy as a contraceptive method. (Kerr and Rogers refes also to ro per cent of all married couples who faI to achieve their desired family size.) In this context. then, artificial insemination may not properly be described as 'therapeutic': it provides no remedf' for infertility, it is a method of circumventing it: the practice may indeed divert attention an resources from the search for the cause of th infertility and its cure. (We may pursue the poinf in relation to a social indication for AID mentione $\$$ elsewhere, the scarcity of babies available fof adoption because of the widespread practice of abortion. The attitudes behind the practice, and the concept of the 'unwanted' child, themselves cate for examination; merely to take them for granted and then to concentrate on providing AID as the alternative to adoption might again be a diversio from a root problem by concentrating on one of its. offshoots or consequences.)

The status of human semen banking is describe as an 'experimental technique' and not as an estabo lished procedure. This must subject it to the ethicat limitations developed in relation to experiment medical procedures in general, particularly as the relate to risk and consent. At a time when governo ments and the possibility of actions for damages oblige pharmaceutical products to be subjected te exhaustive testing before being put into generath clinical use, a less stringent control of humas sperm banking, with its many unknowns, would b inappropriate. The risks call for discrete analyses The risk of disappointment to a man who seekso simply to 'hedge his bet' after vasectomy woul $\Phi$ be the least of them: we cannot invest every mer\& disappointment with a right to its removal. But 角 there are risks of a genetic or social character, the are to be taken more seriously. The 'consent' given by a donor can refer only to the act and its conseo quences so far as they touch himself (and even sa 
consent does not relieve the practitioner of his professional responsibility, particularly in relation to experimental procedures); 'consent' is irrelevant, legally and morally, to harm which ensue to a child or its mother, or to society if social interests are threatened. To argue that the risks are no more, and possibly less, than in normal conceptions is to duck responsibility. Random hazards give no criteria for professional practice. We do not excuse architects from designing buildings that will stand up because trees fall down.

The risks of the transmission of gonorrhoea and genetic diseases, referred to by Mr Frankel, are material here. Even chromosomal analysis, where undertaken, can detect only chromosomal abnormalities present in the donor; it cannot disclose all the genetic possibilities of which he may be the author. Very few recessive single-gene abnormalities can be detected in the heterozygote. Even screening of this sort, therefore, leaves areas of risk to third parties undisclosed; and to accept donors with no more precaution than an enquiry into 'medical and genetic history' would appear to be highly unscientific as well as hazardous. Even assuming honesty and a reasonable accuracy in the replies to questions, there remain many unknowns. And as practices spread - AID itself and embryo transfer on the one side, and undisclosed extramarital conceptions on the other - which make social identity a less and less reliable indication of genetic identity, 'histories', however honestly given, will become less and less reliable as evidence of genetic constitution, and so as pointers to genetic risk. This consideration alone underlines the necessity for a fundamental review of the law and practice relating to the registration of births. It requires also a review of the secrecy which, while protecting the donor and practitioner in artificial insemination from possible legal consequences of their activity, and lessening the risk of emotional involvement between the donor and the recipient marriage, nevertheless gives rise to grave social confusion, especially to unpredictable genetic hazards. It also makes for bad medical science by preventing adequate reporting and objective analysis of the practice by other scientists. The case for such a review is more fully argued in a recent Ciba Foundation symposium on AID and embryo transfer, to which reference may be made (Dunstan, 1973).

The payment of donors, referred to by Mr Frankel and advocated by $\mathrm{Dr}$ Schoysman, invites ethical scrutiny both in relation to the nature of the act and in relation to its consequences. Some things simply cannot be sold: love, for instance. Others, men come to believe - as conscience is enlightened ought not to be sold: human bodies, for instance, whether for prostitution or for slavery; or personal confidences; or the lives of fellow soldiers or citizens in war. There are strong persuasions of this sort in conscience - from an intuitive awareness of the fitness of things - against the sale of both blood and semen, tissues, part of the self with which one is generously endowed, and which one ought not, according to this argument, to sell for profit. 'Freely you have received, freely give' - if give you must.

The moral argument is greatly strengthened by utilitarian considerations of the sort advanced by R M Titmuss in The Gift Relationship (1973). This study demonstrated that where blood is given, as in Britain, the transfusion service is both more economical in cost and clinically more beneficial and less infective than where blood is sold, as in the USA. When money is a consideration, and want or need presses, there are strong inducements to conceal the fact of infection, if known: with hepatitis, for instance, or malaria or syphilis. The same considerations would seem to apply to the sale of semen, with the added factor of the gratification attending the act of masturbation, and of the erotic and other fantasies attaching to the insemination and proxy parenthood. The procedure itself is already ethically so complicated, the position of the donor already so morally ambiguous, that every dictate of prudence, to put it no higher, would point to an exclusion of the cash nexus from the transaction. The donor, if he must donate, must not become a vendor; still less, a vending machine.

Mr Frankel points to the social dangers involved in the possible use of artificial insemination for choosing children of a particular sex. Given an ethics in which it can truthfully be said that 'we are moral beings because we are choosing beings' (Oppenheimer, 1975) it would be hard to affirm dogmatically and $a$ priori that we ought not to want to choose the sex of our children if that became possible. Yet sex is part of that very close complex of biological forces in which randomness and an almost infinite variety appear to have very positive functions in the process of natural selection. To intrude an artificial or chosen selection of sex for no other reason than a mere liking or whim (leaving aside, that is, cases of dominant sex-linked genetic disorders carried by a male) might well introduce a disturbance of the human population structure with adverse social consequences. Intensive research into probable choices and their consequences within different cultures should precede the facilitating of any such choice.

\section{Selecting couples}

Dr Kerr and Miss Rogers begin with a statement on the limited use and value of AIH, and with a proper questioning of the wisdom of mixing semen husband's and a donor's. Apart from the element of self deception to which they point, if our argument above is sound on the new importance, in an age of expanding genetic science, of an accurate knowledge of genetic identity, then the mixing of 
semen merely and unacceptably increases confusion; the offspring of such a union would be indeed filius nullius, with an impersonality more vacuous than any contemplated in those distant ages which coined this apparently insensitive description.

Next they point to the lack of agreed criteria for the selection of recipient couples, and to conflicting opinions on the result of AID. This is because the practice has been developed by isolated practitioners who, because of the cloak of secrecy, have failed to submit their methods to scrutiny in published reports. If the practice is to continue this gap should be filled. There are established methods of concealing identities in scientific reporting, where concealment is ethically required. If practitioners fail to report for fear of legal consequences, then either the law under which they are threatened should be changed or, if the law is well founded, they should desist from a practice which contravenes it. Mere illegality in professional practice is good neither for medicine nor for society.

The restriction of the service to 'married heterosexual unions' looks right. If, as we must assume, the dominant and inescapable interest must be that of the child and his enjoying a normal upbringing an interest, it may be added, which can be overlooked or subordinated to the couple's longing for parenthood - then deliberately to contrive its birth into a lesbian union or to a single woman would be to deny it justice.

When, however, the authors insist that the couple should trust the practitioners so completely as to leave concern over selecting the donor entirely to them, then it must be replied that this insistence presupposes ground for trust, and that this ground does not yet exist: the criteria for donor selection have not yet been publicly authenticated as they should be.

\section{Selecting donors}

This is the subject of Dr Schoysman's paper.

Among the criteria listed for the donor is one that 'his morality should be good'. Why? Morality is not carried genetically: it is not something which he can give to his offspring, except through a parental relationship and from this he is excluded. Perhaps the donor's 'morality' is thought of as a safeguard against concealment or deceit as to his own genetic purity, or against subsequent curiosity about his child. But if so, how is his 'morality' assessed? In fact the sort of 'morality' to be looked for is that of a man who, in this description - perhaps the brother of the infertile husband - must be married with at least two children of his own, 2 who, with or without the knowledge and consent $\vec{F}$ of his wife, will, ideally when visiting her in the maternity ward after the birth of his own child, consent to become a donor by masturbation and to be paid for doing so, foregoing all knowledge, noto only of who will bring up the child of his loins, buto even whether his semen has been used at all, lest $\overline{\bar{p}}$ later in life he should 'become bothered by the fact $\mathbb{\Phi}$ that somewhere a child of him lives'. The more one reflects upon the aID transaction, the stronger the conviction grows that it is about the donor that the $\mathrm{P}$ most searching ethical questions must be asked; $\overrightarrow{\vec{\omega}}$ and then about the doctor's use of him as ano accomplice in his deed.

What practical outcome must be looked for, therefore, from yet another discussion of AID? It must surely be, for Britain, the setting up of a newi and expert body to do again, and with new thorough- 0 ness, what a departmental committee of the Home Office did in I960 (Feversham, 1960). The argu- $-\vec{D}$ ment of the Feversham Report is out of dateo scientifically, medically, legally, and socially. The whole question must be re-examined in all its aspects by a government prepared, not only to initiate the enquiry, but also to legislate, once $a$ clear basis for legislation is established, in order tos protect serious personal, professional and sociaf interests. The coming of commercial sperm banks adds urgency to this necessity: the matter can no longer be ignored. In other countries, no doubt, $\overrightarrow{\vec{A}}$ the urgency is no less.

\section{References}

Curran, C E (1973). Politics, Medicine and Christiar Ethics.

Dunstan, G R (1973). Moral and social issues arising from AID, in Wolstenholme and Fitzsimmons, infra, $1973 e^{\circ}$

Dunstan, G R (1974). The Artifice of Ethics. cap. 4 Feversham, Lord (1960). Report of the Departmentaf Committee on Human Artificial Inseminations Cmnd I I05.

Jones, A, and Bodmer, W (1974). Our Future Inherit ance, Choice or Chance?, I-74.

Oppenheimer, Helen (1975). 'Ought and is', in G RO Dunstan, ed, Duty and Discernment.

Ramsey, P (1970). Fabricated Man.

Titmuss, R M (1973). The Gift Relationship: From Human Blood to Social Policy.

Wolstenholme, G E W, and Fitzsimmons, D (1973) The Law and Ethics of AID and Embryo Transfer. T 